\title{
AQUISIÇÃO DA CODA SIMPLES E COMPLEXA COM /S/ EM CRIANÇAS COM DESVIO FONOLÓGICO
}

\author{
The acquisition of simple and complex coda /S/ \\ in children with phonological disorder
}

\author{
Carolina Lisbôa Mezzomo ${ }^{(1)}$, Vanessa Giacchini (2), Roberta Freitas Dias ${ }^{(3)}$, \\ Simone Weide Luiz ${ }^{(4)}$, Silvana Gonçalves Lopes ${ }^{(5)}$
}

\begin{abstract}
RESUMO
Objetivo: descrever a produção das codas finais simples e complexa com /S/ em crianças com desvio fonológico e verificar a influência de variáveis linguísticas e extralinguísticas na aquisição das mesmas. Método: foram utilizados dados de fala de 66 crianças com desvio fonológico, 33 meninos e 33 meninas, entre 3:0 e 9:0. As amostras de fala foram coletadas transversalmente, com base no instrumento Avaliação Fonológica da Criança. Foram analisadas apenas as palavras alvo contendo coda simples lexical (ex.: talvez), coda simples morfológica (ex.: casas), coda complexa composta por nasal e fricativa (ex.: parabéns) e coda complexa com glide e fricativa (ex.: dois), totalizando um corpus de 481 palavras. Para ambos os tipos de coda foram consideradas como variáveis dependentes a produção correta do /S/, a omissão da coda ou sua substituição. Como variáveis intervenientes consideraram-se os fatores extralinguísticos idade, sexo e grau do desvio e as variáveis linguísticas classe gramatical, tonicidade, número de sílabas, contexto precedente e tipo de coda. Os dados de fala foram analisados estatisticamente através do VARBRUL, com grau de significância de 5\%. Resultado: o programa estatístico selecionou como significante para a produção correta das codas simples e complexas as variáveis classe gramatical, tipo de coda e a gravidade do desvio em ordem decrescente de relevância estatística, com valor de $p<0,001$. Conclusão: verificou-se que as variáveis gravidade do desvio, tipo de coda e classe gramatical influenciam de forma significante a produção das codas finais simples e complexas com o arquifonema /S/, em crianças com desvio fonológico.
\end{abstract}

DESCRITORES: Distúrbios da Fala; Fala; Linguagem Infantil

(1) Fonoaudióloga; Professora Adjunta do Curso de Fonoaudiologia da Universidade Federal de Santa Maria - UFSM, Santa Maria, RS, Brasil; Doutora em Linguística Aplicada pela Pontifícia Universidade Católica do Rio Grande do Sul, Porto Alegre, RS, Brasil.

(2) Fonoaudióloga da Associação de Pais e Amigos dos Excepcionais de Marau, RS, Brasil; Mestre em Distúrbios da Comunicação Humana UFSM, Santa Maria, RS, Brasil.

(3) Fonoaudióloga; Professora do Curso de Fonoaudiologia da UFSM; Mestre em Distúrbios da Comunicação Humana UFSM, Santa Maria, RS, Brasil.

(4) Licenciada em Letras Português-Inglês; Mestranda do Programa de Pós-Graduação em Distúrbios da Comunicação Humana da UFSM, Santa Maria, RS, Brasil.

(5) Graduanda do Curso de Fonoaudiologia da UFSM, Santa Maria, RS, Brasil. Bolsista do Fundo de Incentivo à Pesquisa - FIPE.

Trabalho realizado na Universidade Federal de Santa Maria UFSM, Santa Maria RS, Brasil.

Conflito de interesses: inexistente

\section{INTRODUÇÃO}

O Português Brasileiro (PB) apresenta 16 consoantes na posição de onset inicial $(p, b, t, d, k, g, f$, $\left.v, s, z, \int, 3, m, n, I, R\right)$ e 19 em onset medial ( $p, b, t$, $\mathrm{d}, \mathrm{k}, \mathrm{g}, \mathrm{f}, \mathrm{v}, \mathrm{s}, \mathrm{z}, \mathrm{J}, 3, \mathrm{~m}, \mathrm{n}, \mathrm{n}, \mathrm{l}, \kappa, \mathrm{r}, \mathrm{R})$. Já a posição de coda, isto é, no final da sílaba, impõe limitações ao material segmental que lhe pode ser associado, sendo as consoantes /S/, /R/, /L/ e /N/ as de maior ocorrência nesta posição ${ }^{1-4}$.

Segundo a teoria métrica, a estrutura silábica do PB apresenta um núcleo obrigatório, que apresenta o maior grau de soantidade e é sempre preenchido por vogais. A rima, além de ter um núcleo, pode ser composta por uma coda, preenchida por soante ou /S/. Já o ataque (ou onset), contém dois elementos no máximo, sendo o segundo, sempre uma consoante não nasal ${ }^{5}$, conforme a Figura 1. 


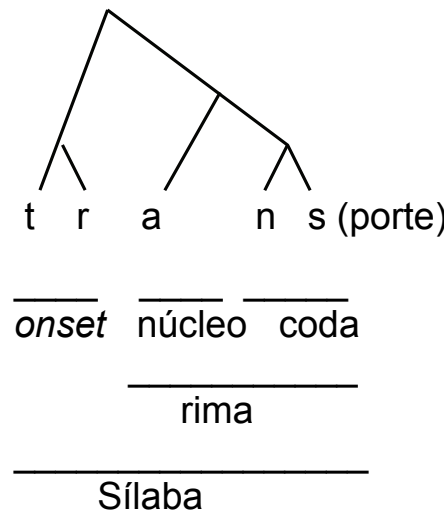

Figura 1 - Representação da estrutura silábica, segundo a fonologia métrica

Dentre os segmentos pós-vocálicos, a coda com fricativa pode ser de dois tipos, lexical ou morfológica. A coda lexical é um constituinte que faz parte do item lexical aprendido, ou seja, sua ausência pode criar um novo item lexical (nós versus nó) ou simplesmente criar um item lexical desprovido de sentido (lápis versus lapi). Por outro lado, a coda morfológica é vista como um morfema unido à palavra, que atribui a noção de quantidade. A coda morfológica carrega uma significância de número (ex.: balas, mesas $)^{6}$.

Além da coda simples, discutida até o momento, outros padrões silábicos travados são encontrados no PB, são eles: VCC, CVCC e CCVCC. Nesses casos, duas consoantes tautossilábicas formam uma coda complexa. Essas estruturas resumem-se à sequência "soante + /S", sendo /ns/ (ex.: mons. tro), /rs/ (ex.: pers.pi.caz) e /ls/ (ex.: sols.tí.cio) as combinações realizadas 6 .

No que se refere à aquisição das consoantes no $\mathrm{PB}$, observa-se que o padrão de desenvolvimento sem desvio ou típico, comum à maior parte das crianças se dá entre quatro e seis anos de idade, respeitando variações individuais. Existe uma variabilidade tanto no domínio segmental quanto no domínio prosódico dentro do desenvolvimento linguístico das crianças ${ }^{7}$. Há o surgimento da linguagem expressiva nos primeiros anos de vida da criança, período em que os fonemas são adquiridos e estabelecidos quanto às posições nas sílabas e nas palavras e de acordo com uma cronologia que parece similar para a maioria das crianças.

Autores mencionam que, de um modo geral, a fricativa /S/ em coda lexical surge e é adquirida depois dos arquifonemas /L/ e $/ \mathrm{N} /$ e antes do $/ \mathrm{R} /{ }^{8}$. A emergência e domínio da fricativa em coda final ocorrem aos um ano e seis meses e dois anos e seis meses respectivamente. Por isso, a produção correta da coda final preenchida pelo segmento /S/ é considerada tardia na aquisição, podendo constituir uma coda simples lexical (ex. tênis, lápis) ou morfológica (ex. mesas, canetas); ou uma coda complexa nas sílabas VGC - vogal/glide/consoante (ex.: Deus) e VCC - vogal/consoante/consoante (ex.: parabéns) ${ }^{6}$.

Quando a criança não consegue adquirir o sistema fonêmico da sua língua materna na idade prevista, pode-se estar diante de um caso de desvio fonológico, também chamado distúrbio fonológico. O desvio fonológico pode ser definido como uma alteração de fala caracterizada pela produção inadequada dos sons e uso incorreto das regras fonológicas da língua, resultando no colapso de contrastes fonêmicos. A causa do desvio é desconhecida, havendo variação na gravidade e na inteligibilidade de fala. Para certos autores, o desvio não significa um sistema sem ordem, mas simplesmente um sistema cujos padrões não são idênticos à norma, como um subsistema dentro do sistema do $\mathrm{PB}{ }^{9}$. Parece haver regularidade nas "substituições" (p.e. fricativas bilabiais são substituídas por plosivas bilabiais, o mesmo ocorrendo para alveolares e palatais, respectivamente; ou fones vozeados são substituídos por seus pares não-vozeados etc.).

Nos casos de desvio fonológico, as codas, geralmente, apresentam-se alteradas, principalmente, aquelas de aquisição tardia no desenvolvimento típico, como o arquifonema $[S]$ e $[R]^{6}$. Entre as fricativas que podem ocupar o lugar de coda encontram-se as fricativas alveolar e palatal, dependendo do dialeto, que correspondem ao arquifonema [S]. Além destas, também podem estar presentes foneticamente as fricativas uvulares, faríngeas e glotais, que, em função da variação dialetal, correspondem ao arquifonema [R], juntamente com as vibrantes múltipla, simples ou palatal ${ }^{5}$. Estas dificuldades na aquisição dos componentes da língua provocam na maioria dos casos ininteligibilidade de fala, tornando a mensagem ambígua para seu interlocutor. As crianças com desvio fonológico desenvolvemse de forma semelhante às outras, portanto, sem dificuldades de aprendizagem geral, ausência de déficits intelectual e auditivo, cognitivo ou fatores orgânicos conhecidos $^{10}$ estando sua dificuldade exclusivamente na aquisição do sistema fonético/ fonológico da língua.

Para a definição do diagnóstico de desvio fonológico, além de se identificar o inventário fonético da criança, é necessário analisar todas as estruturas silábicas presentes na amostra de fala e a distribuição dos sons nessas estruturas ${ }^{2}$. Assim, o objetivo desse estudo foi descrever a produção da coda simples (morfológica ou lexical) e da coda complexa com /S/, em final de palavra, em crianças 
com desvio fonológico. Além disso, analisou-se a influência de variáveis linguísticas e extralinguísticas durante a produção das mesmas, com vistas a facilitar a terapia de fala com a utilização de ambientes facilitadores.

\section{MÉTODO}

Esta é uma pesquisa exploratória, quantitativa e de caráter transversal em que foram utilizados dados de fala de 66 crianças com diagnóstico de desvio fonológico, sendo 33 meninos e 33 meninas, com idades entre três e nove anos, todos falantes monolíngues do PB.

As amostras de fala consideradas neste estudo fazem parte de um banco de dados criado a partir da realização de dois projetos de pesquisa ${ }^{13,17,27}$. Para a formação do banco de dados as crianças foram submetidas a um processo de triagem fonoaudiológica e receberam diagnóstico de desvio fonológico. As amostras de fala foram coletadas transversalmente, com base no instrumento "Avaliação Fonológica da Criança - AFC"'. Este instrumento proporciona a nomeação espontânea de 125 palavras, através de cinco desenhos temáticos.

O AFC foi aplicado individualmente com cada uma das crianças, sendo os dados de fala registrados utilizando-se um gravador digital. Após, os dados foram transcritos por meio de transcrição fonética restrita e revistos por mais dois julgadores - acadêmicos do curso de Fonoaudiologia - com experiência em transcrição fonética, separadamente. A partir da análise contrastiva, foi determinado o sistema fonológico de cada criança e após, foi calculado o índice Percentual de Consoantes Corretas - Revisado (PCC-R) ${ }^{11}$. O PCC-R é baseado no cálculo do $\mathrm{PCC}^{12}$ que pode ser obtido, dividindose o número de consoantes corretas pelo número de consoantes corretas, mais o número de consoantes incorretas, multiplicando-se o valor obtido por cem. No PCC-R, entretanto, não são considerados como erros as distorções fonéticas.

Assim, a gravidade do desvio é classificada como: Desvio Grave, com PCC menor que 50\%; Desvio Moderado-Grave, com PCC entre $51 \%$ e $65 \%$; Desvio Leve-Moderado, com PCC entre $66 \%$ e $85 \%$ e Desvio Leve, com PCC maior que $86 \%$. Quanto mais grave é o desvio, mais ininteligível é a fala ${ }^{13}$.

Para este estudo, foram levantadas do banco de dados apenas as palavras alvo contendo coda simples lexical (ex.: talvez), coda simples morfológica (ex.: casas), coda complexa composta por nasal e fricativa (ex.: parabéns) e coda complexa com glide e fricativa (ex.: dois). Dessa forma, o corpus foi composto por 481 palavras, que foram codificadas conforme produzidas, isto é, de forma correta ou incorreta e de acordo com as variáveis linguísticas e extralinguísticas.

Tanto para a coda simples como para a coda complexa, consideraram-se como variantes da variável dependente a produção correta do /S/, a omissão da coda (ex.: luz ['lu]), a substituição (ex.: palatalizada - lápis ['lapij]), a metátese (ex.: mais ['masi]), e ressilabação fruto de epêntese vocálica (ex.: óculos [ku'loso]).

Como variáveis intervenientes, foram considerados os fatores extralinguísticos idade (faixa etária), sexo e gravidade do desvio fonológico e as variáveis linguísticas classe gramatical, a tonicidade, o número de sílabas, o contexto precedente e o tipo de coda.

Para uma análise eficiente da variável idade, foram analisadas três faixas etárias, considerandose como faixa inicial dos três aos quatro anos e 11 meses, a segunda dos cinco aos seis anos e 11 meses e a última faixa etária dos sete aos nove anos. Quanto à variável sexo, foi realizada a análise da fala de 33 meninas e 33 meninos, conforme referido anteriormente. Esse aspecto foi considerado pelo fato de já ter sido mencionado em outros estudos como sendo um fator que confere uma diferença na aquisição da linguagem ${ }^{14,15}$. Para a gravidade do desvio considerou-se as seguintes variantes, segundo o (PCC-R $)^{11}$ desvio leve, desvio leve-moderado, desvio moderado-grave e desvio grave.

Quanto ao fator classe gramatical, considerouse as variantes palavras de conteúdo (ex.: substantivos, os adjetivos, os verbos, os advérbios e os numerais) e palavras funcionais (ex.: artigos, as preposições, as conjunções, os pronomes e as interjeições). A tonicidade foi analisada nas variantes tônica (ex.: português), pós-tônica (ex.: lápis) e póspós-tônica (ex.: ônibus), pois o tipo de coda analisado permite apenas estas ocorrências. Dentro da variável número de sílabas foi possível analisar as codas em itens lexicais monossílabos, dissílabos, trissílabos e polissílabos. Em relação à variante contexto precedente fizeram parte as vogais: dorsal /a/ (ex.: águas), dorsal labial /o/ e /u/ (ex.: robôs, cactus), coronal /e/ e / i/ (ex.: inglês, Paris), além dos glides [j, w] (ex.: iguais, paus). No que se refere ao tipo de coda, as palavras foram categorizadas como coda simples lexical (ex.: paz), coda simples morfológica (ex.: pastas), coda complexa composta por glide e fricativa (ex.: mais) ou coda complexa com nasal e fricativa (ex.: armazéns).

Todas as produções das crianças foram classificadas e categorizadas de acordo com as variáveis e variantes anteriormente descritas. Essa categorização foi digitada em um formulário no programa 
Microsoft Office Access 2003, que serviu de entrada para o programa estatístico.

Os dois projetos de pesquisa responsáveis pela composição do banco de dados pesquisado foram aprovados pelo Comitê de Ética e Pesquisa da Universidade Federal de Santa Maria, sob número 6331.e 064/2004. Os pais e/ou responsáveis pelas crianças que fizeram parte dos bancos de dados foram devidamente esclarecidos sobre os objetivos e procedimentos da pesquisa, autorizando a participação das mesmas por meio do Termo de Consentimento Livre e Esclarecido.

Para a realização da análise estatística contou-se com o uso do Pacote Computacional VARBRUL ${ }^{16}$. Esse conjunto de programas é largamente utilizado em análises sociolinguísticas. Entretanto, este programa já vem sendo usado com sucesso, desde a década de $90 \mathrm{com}$ dados de aquisição da linguagem ${ }^{7,14,15,17}$. Utilizou-se o pacote VARBRUL pelas características e objetivos do presente estudo e pelo fato de ele ser capaz de fornecer frequências, probabilidades e selecionar variáveis estatisticamente significantes sobre os dados estudados. O programa faz a análise probabilística na forma binária. Isto significa que esse programa, por meio de cálculos estatísticos, atribui pesos relativos às variantes das variáveis independentes, com relação às duas variantes (produção correta e incorreta) do fenômeno linguístico em questão, representadas pela variável dependente. Deve-se enfatizar que o
VARBRUL atribui valores de significância às variáveis linguísticas e extralinguísticas através da interação entre as mesmas (ex. sexo versus idade; tonicidade versus número de sílabas). Dessa forma, ele não atribui valor de $p$ às variantes contidas dentro de uma variável. Por exemplo, o VARBRUL não gera um valor de significância na comparação entre o sexo masculino e o feminino. Para essas variantes, são atribuídos pesos relativos, isto é, a probabilidade maior ou menor de interferência das mesmas na produção da fricativa em coda. Os pesos relativos ou probabilidades de ocorrência da fricativa em coda foram retirados da interação estatística que continha todas as variáveis selecionadas como significantes pelo programa. Valores de peso relativo abaixo de .50 foram considerados desfavorecedores da produção correta. Valores probabilísticos entre .50 a .59 foram considerados neutros. Por fim, valores iguais ou acima de .60, foram favorecedores da produção correta da fricativa em coda.

\section{RESULTADOS}

O programa estatístico selecionou três variáveis relevantes para produção correta das codas simples (lexical e morfológica) e complexa. São elas a classe gramatical, o tipo de coda e a gravidade do desvio em ordem decrescente de relevância estatística com valor de $p<0,001$ (ver Figura 2).

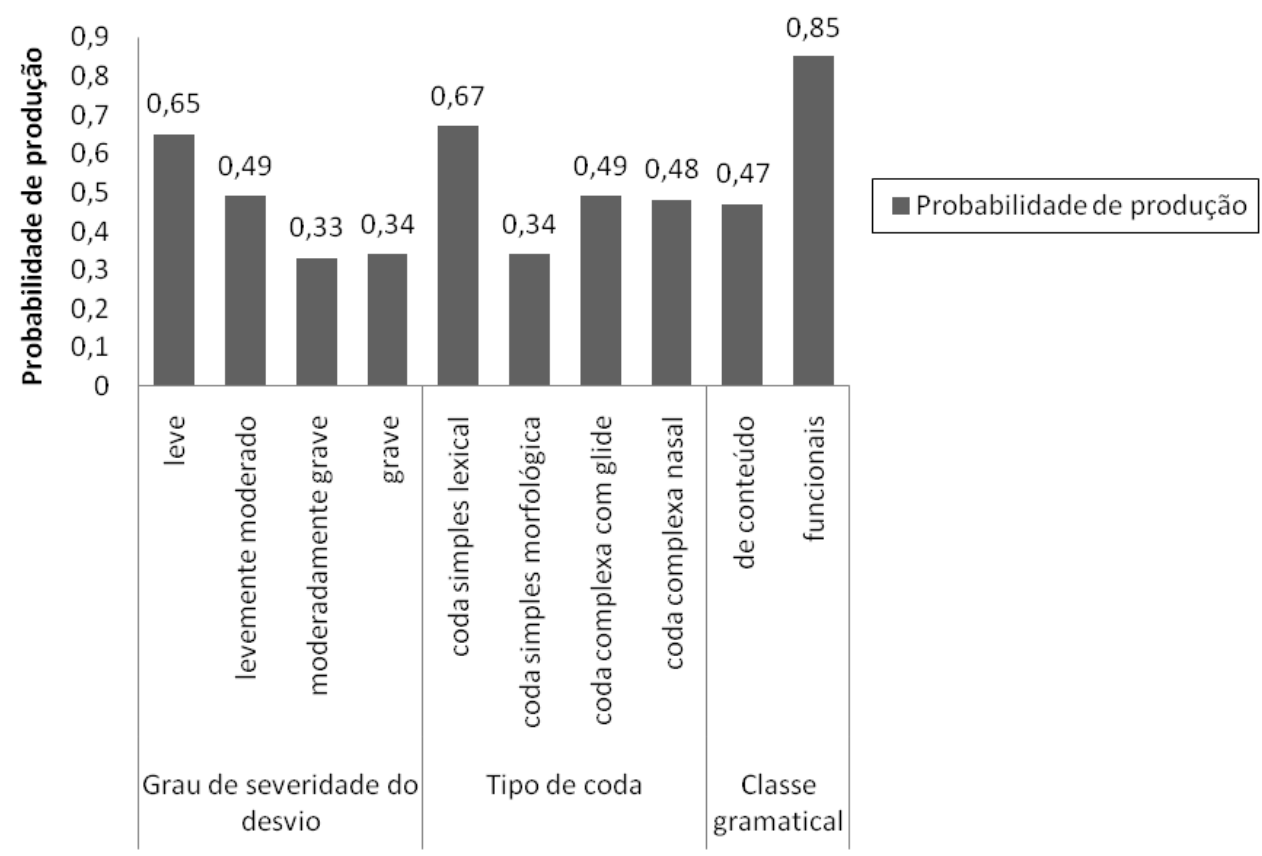

Legenda: Programa estatístico: Varbrul; $p<0,05$

Figura 2 - Variáveis relevantes à produção correta das codas simples (lexical e morfológica) e complexa 
produção da coda lexical e os numerais na aquisição da coda morfológica, já os verbos não se mostraram favorecedores em nenhum dos tipos de coda ${ }^{17}$.

De acordo com pesquisa realizada, artigo, numeral e pronome, que são vistas como palavras funcionais, tendem a receber mais marcas explícitas de plural, ocorrendo apenas no determinante ou em elementos mais à esquerda do sintagma nominal, geralmente no primeiro elemento ${ }^{18}$. Esse fato é corroborado em outro estudo em que as crianças realizam a marcação de plural de forma efetiva em artigos, mas não o realizam em substantivos. Observa-se dessa forma, a aplicação por parte dessas crianças da regra de simplificação linguística, também utilizada pelos adultos como marca sociolinguística, determinando a variação de número em apenas um dos elementos do sintagma, e não em ambos ${ }^{17}$ (ex.: "as menina").

Portanto, as palavras funcionais (ou palavras de classe fechada) apresentam um significado gramatical, elas são índices de propriedades gramaticais que fazem a diferença entre as línguas. Essas palavras exercem principalmente funções sintáticas, servindo como elementos de ligação frasal com baixa carga semântica própria ${ }^{19}$.

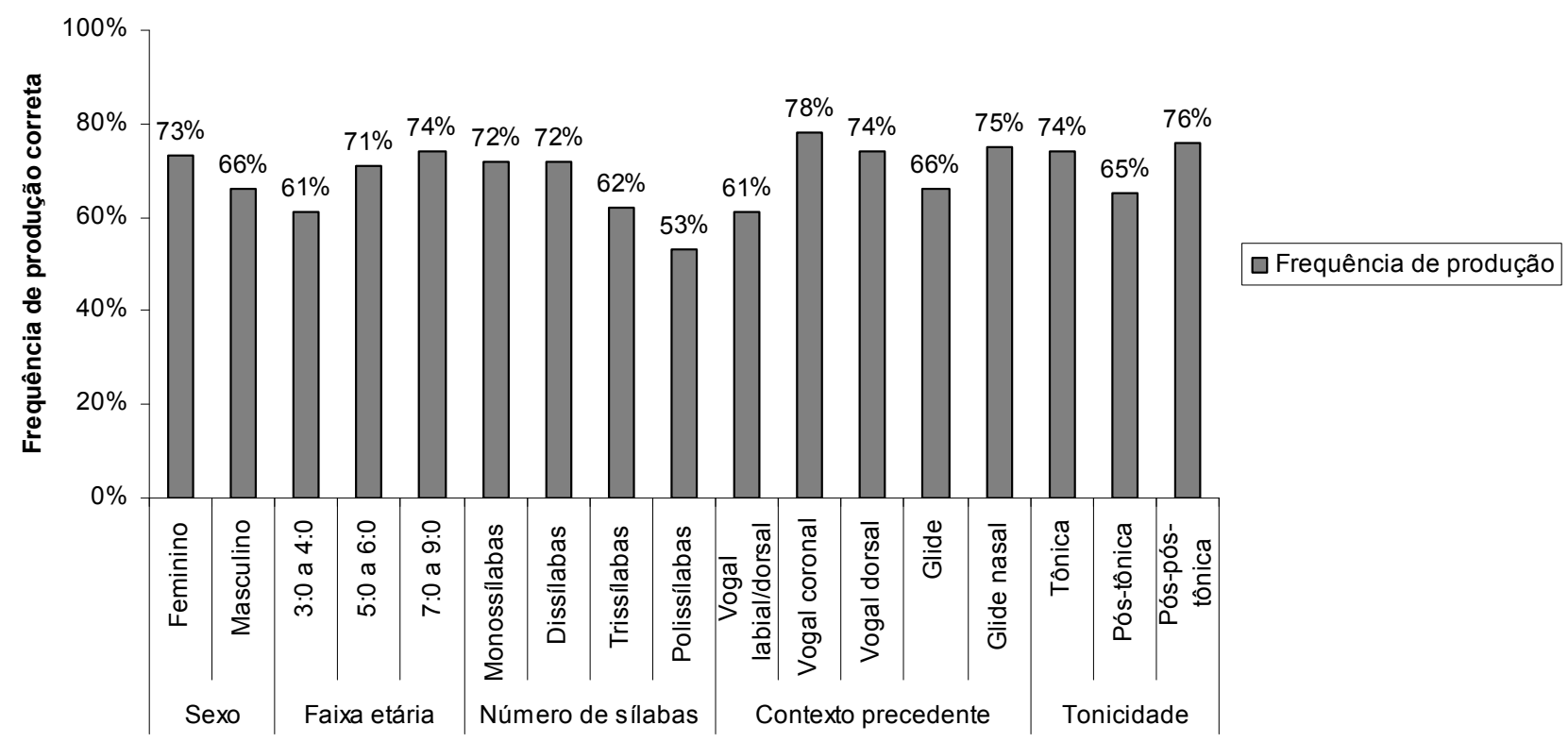

Figura 3 - Frequência de produção correta das codas simples (lexical e morfológica) e complexa

Em relação à classe gramatical, os resultados demonstraram que as palavras funcionais (artigos, as preposições, as conjunções, os pronomes e as interjeições) apresentam maior probabilidade e frequência (89\%) de produção correta do /S/ (ex.: nós, mas,os).

No que se refere ao tipo de coda, a produção correta é beneficiada quando esta tem uma função distintiva, representando uma coda simples lexical, podendo-se supor que a coda lexical é mais fácil de ser produzida corretamente e mais precocemente do que as codas morfológica e complexa (ex.: lápis, nariz, luz).

O desvio fonológico de grau leve destacou-se como favorecedor da produção correta com alta probabilidade de produção.

As demais variáveis não foram relevantes à produção das codas. Contudo, observa-se maior frequência de produção correta nos indivíduos de sexo feminino, na faixa etária de 7:0 a 9:0, em palavras monossilábicas e dissilábicas, com contexto precedente composto por vogal coronal e em sílaba pós-pós-tônica, conforme Figura 3.

\section{DISCUSSÃO}

Dentre as variáveis linguísticas, a classe gramatical foi selecionada como estatisticamente significante. O programa VARBRUL apontou como favorecedoras a produção de palavras funcionais como conjunções, preposições, artigos, verbos e advérbios. Este resultado coincide, parcialmente, com o encontrado em um estudo no qual o programa apontou como favorecedores os pronomes e advérbios na aquisição das codas lexicais e morfológica, enquanto os substantivos foram favorecedores na 
A variável tipo de coda foi também selecionada como estatisticamente significativa, sendo a variante coda simples lexical a variável que apresenta maior probabilidade de ser produzida corretamente.

Esse resultado vai ao encontro dos obtidos em um estudo com dados de aquisição típica do holandes ${ }^{20}$. Neste estudo os resultados apontam para o aparecimento da coda simples com fricativa no segundo estágio de desenvolvimento da rima silábica (VC), enquanto que a coda complexa (chamada de consoante extra-rima) surge no quarto e último estágio de desenvolvimento da rima, fornecendo evidências para uma rima biposicional, mais uma consoante (VCC ou VGC) ${ }^{20}$.

Por outro lado, os achados aqui apresentados concordam com outro estudo sobre o desenvolvimento fonológico típico do PB, o qual mostra que a idade de aquisição da coda fricativa em final de palavra se dá aos dois anos e seis meses. Sendo que a primeira produção correta de coda lexical ocorre aos dois anos e dois meses e de coda morfológica aos dois anos e quatro meses, ou seja, a lexical é mais precoce que a morfológica ${ }^{21}$. Segundo outro estudo, sobre o PB, também verificou-se que o surgimento das rimas complexas (VGC, VCC) na fala das crianças brasileiras, não poderia ser caracterizado como uma aquisição tardia. Essas estruturas desenvolvem-se de modo similar à coda simples com /S/, mesmo contendo mais elementos e parecendo ser mais complexas do que esta última ${ }^{22}$.

Os dados do presente estudo podem encontrar justificativa no fato de a criança possuir primeiro a rima VC para, aí sim, representar a marca de plural em coda ${ }^{23}$. Isso implica que os níveis prosódicos devem, primeiramente, abrir caminho e, somente quando a posição de coda se tornar disponível a morfologia desempenhará um papel ${ }^{24,25}$.

A variável extralinguística gravidade do desvio mostrou-se significativa a produção correta do fenômeno estudado. Quando se tratava de grau leve, a coda (simples ou complexa) com fricativa obteve maior probabilidade de produção correta, embora a gravidade, muitas vezes, seja um aspecto negligenciado pela fonologia clínica ${ }^{26}$. Outro estudo corrobora os achados apresentados, já que afirma que as crianças com maior gravidade de desvio apresentam maior uso de estratégias de reparo, ou seja, não produzem o alvo correto ${ }^{13}$. Dessa forma, entende-se que a maior gravidade do desvio está relacionada à presença de um maior número de sons não adquiridos no sistema fonológico ${ }^{27}$.

Esse resultado também pode estar relacionado ao fato de que os graus leve e leve-moderado são os mais detectados nas crianças com desvio fonológico como mostra uma pesquisa com 50 sujeitos com idades entre quatro e 11 anos falantes do PB'

Percebeu-se que as demais variáveis não foram favorecedoras à produção das codas, porém observou-se maior frequência de produção correta em indivíduos do sexo feminino que em indivíduos do sexo masculino, dados também verificados em outro estudo ${ }^{17}$. Tal resultado discorda do encontrado por estudo em que verificou maior frequência e probabilidade de produção correta da fricativa em coda final pelo sexo masculino ${ }^{14}$

Em relação à variante faixa etária, as crianças mais velhas (acima de sete anos) têm uma maior probabilidade de produção correta, embora não sendo estatisticamente significante. Um estudo constatou que à medida que a idade avança, ocorre um crescimento na produção correta dos fonemas até atingir uma alta porcentagem de produção correta, que representa a estabilização do uso. No entanto, a presença de regressões de uso foi verificada durante o processo de domínio da coda ${ }^{14}$.

As palavras menores (monossilábicas e dissilábicas), com contexto precedente composto por vogal coronal e em sílaba pós-pós-tônica assumem um ambiente favorecedor, porém não significante. Estas informações são confirmadas em uma pesquisa realizada, na qual a autora verificou que a coda final /S/ é favorecida pela sílaba átona ${ }^{28}$. Contudo, tal resultado discorda com o encontrado em pesquisa que observou favorecimento da produção correta das coda lexicais quando presente em sílabas tônicas ${ }^{17}$.

\section{CONCLUSÃO}

Verificou-se, a partir dos resultados deste estudo, que as variáveis selecionadas gravidade do desvio fonológico, classe gramatical e tipo de coda influenciaram a produção fonológica da coda no corpus analisado. A produção do arquifonema /S/ em final de sílaba é significativamente favorecida em crianças com desvio fonológico quando a gravidade do desvio for leve, quando se tratar de palavras funcionais (artigos, as preposições, as conjunções, os pronomes e as interjeições) e em coda simples lexical.

O presente estudo procura servir de base para trabalhos com a produção da coda com o arquifonema /S/ na fala com desvio ou alteração. Contribui, dessa forma, com o processo terapêutico, acelerando assim sua evolução. 


\section{ABSTRACT}

Purpose: to describe the production of final simple and complex coda with /S/ in children with phonological disorder, verifying the influence of linguistic and extra-linguistic variables in codas acquisition. Method: we utilized speech data from 66 children with phonological disorder, 33 boys and 33 girls, aged between 3:0 and 9:0. Speech samples were collected through a crossed-nature study, using the instrument referred to as Child Phonological Evaluation ${ }^{1}$, with 481 words being part of the database from a project which was approved by the Ethics Research Committee (CEP) of the institution. Next, the words were statistically analyzed through the statistical program VARBRUL, considering a significance level of $5 \%$. We took into account as dependent variables the correct production of /S/, the omission of the coda or its substitution. As intervening variable, we considered the extra-linguistic factors age, sex, degree of the phonological disorder; and the linguistic variables grammatical class, tonicity, precedent context, and type of coda. Results: the statistical program selected as statistically significant for the correct production of simple and complex coda, the degree of the phonological disorder, the type of coda, and the grammatical class, with the value of $p<0.01$. Conclusion: we verified, through this study, that the degree of phonological disorder, type of coda, and grammatical class influenced in a significant way on the production of final simple and complex coda with the archiphoneme /S/, in children with phonological disorder.

KEYWORDS: Speech Disorders; Speech; Child Language

\section{REFERÊNCIAS}

1. Keske-Soares M, Blanco APF, Mota HB. O desvio fonológico caracterizado por índices de substituição e omissão. Rev. Soc. Brás Fonoaudiol. 2004; 9(1): 10-8.

2. Wertzner HF, Pagan LO, Galea DES, Papp ACCS. Características fonológicas de crianças com transtorno fonológico com e sem histórico de otite média. Rev. Soc. Brás Fonoaudiol. 2007; 12:41-7.

3. D'Angelis WR. Sistema fonológico do Português: rediscutindo o consenso. DELTA: Documentação de Estudos em Lingüística Teórica e Aplicada. 2008; 18(1): 1-24.

4. Galea DES, Wertzner HF. Comparação entre onset e coda silábica durante a aquisição fonológica. Rev. Soc. Brás Fonoaudiol. 2010; 15(1): 103-7.

5. Bisol L. Introdução a estudos de fonologia do português brasileiro. $4^{a}$ ed. Porto Alegre - Rio Grande do Sul: EDIPUCRS, 2005. ISBN 85-7430-529-4.

6. Mezzomo, CL. Sobre a aquisição da coda. In.: LAMPRECHT, R. R. (Org.). Aquisição Fonológica do Português: perfil de desenvolvimento e subsídios para terapia. Porto Alegre: Artmed, 2004.

7. Garcia R, Zimmer M. O papel da frequência lexical e segmental na aquisição das fricativas em crianças de um a três anos: uma perspectiva dinâmica na aquisição do português brasileiro. Acta Sci Lang Cult. Maringá. 2010; 32(2): 279-89.

8. Mezzomo CL, Quintas VG, Savoldi A, Bruno LB. Aquisição da coda: um estudo comparativo entre dados transversais e longitudinais. Rev. Soc. Brás Fonoaudiol. 2010; 15(3): 401-7.

9. Yavas M, Hernandorena C, Lamprecht R. Avaliação fonológica da criança. Porto Alegre: Artes Médicas; 1991.

10. Nunes DA, Payão LMC, Costa RCC. Desvios fonológicos na educação infantil. Rev CEFAC. 2010; 12(2):331-6.

11. Shriberg LD, Austin D, Lewis BA, McSweeny $\mathrm{JL}$, Wilson DL. The speech disorders classification system (SDCS): extensions and lifespan reference data. J Speech Hear Res. 1997; 40(4):723-40.

12. Shriberg LD, Kwiatkowski J. Phonological disorders I: a diagnostic classification system. J Speech Hear Disord. 1982; 47:226-41.

13. Ghisleni MRL, Keske-Soares M, Mezzomo CL. $\mathrm{O}$ uso das estratégias de reparo, considerando a gravidade do desvio fonológico evolutivo. Rev. CEFAC. 2010;12(5):766-71.

14. Athayde ML, Baesso JS, Dias RF, Giacchini V, Mezzomo CL. O papel das variáveis extralinguísticas idade e sexo no desenvolvimento da coda silábica. Rev. Soc. Brás Fonoaudiol. 2009; 14(3) 293-9.

15. Moura SRS, Mezzomo CL, Cielo CA. Estimulação em consciência fonêmica e seus efeitos em relação à variável sexo. Pró-Fono. 2009; 21(1):51-6.

16. Cedergren HJ, Sankoff D. Variable rules: performance as a statistical reflection of competence. Language. 1974; 50(2): 333-55.

17. Mezzomo CL, Mota HB, Dias RF, Giacchini V. Fatores relevantes para aquisição da coda lexical e 
morfológica no português brasileiro. Rev. CEFAC. 2010; 12(3): 412-20.

18. Martins FS. Uma abordagem sociolinguística da concordância nominal de número no falar dos habitantes do município amazonense de Benjamin Constant. Anais do IX Encontro do CELSUL, Palhoça, SC, out. 2010 Universidade do Sul de Santa Catarina.

19. Juste F, Andrade CRF. Tipologia das rupturas de fala e classes gramaticais em crianças gagas $\mathrm{e}$ fluentes. Pró-Fono. 2006; 18(2):129-40.

20. Fikkert, P. 'On the acquisition of rhyme structure in Dutch'. In: R. Bok-Bennema \& C. Cremers (eds.), Linguistics in the Netherlands. Amsterdam: John Benjamins. 1994; 37-48.

21. Augusto, R. A influência do tipo de coda na aquisição do português brasileiro. 18은 Simpósio de Iniciação Científica da USP. 2010. Nov. 16-19; Ribeirão Preto. São Paulo. USP, 2010

22. Mezzomo, CL. A aquisição das estruturas silábicas complexas VCC e VGC. Anais do XIV Congresso Brasileiro de Fonoaudiologia; 2006 Out. 04-07; Salvador. Bahia: SBFa, 2006.

23. Tyler AA, McOmber LS. Examining phonologicalmorphological interactions with converging sources of evidence. Clinical Linguistics \& Phonetics.1999; 13(2), 131-56.

24. Lléo C. Prosodic licensing of codas in the acquisition of Spanish. Probus. 2003; 15(2003), 257-81.

25. Ribas LP. Aquisição das líquidas por crianças com desvio fonológico: Aquisição silábica ou segmental? Rev. Letras - UFSM. 2008 ; (36):129-49. 26. Prezas RF, Hodson BW. Diagnostic evaluation of children with speech sound disorders. Encyclopedia of Language and Literacy Development (pp. 1-8). London, ON: Canadian Language and Literacy Research Network. Retrieved May 10, 2007, Available from: http://literacyencyclopedia.ca/pdfs/ Diagnostic_Evaluation_of_Children_with_Speech_ Sound_Disorders.pdf

27. Keske-soares M, Brancalioni AR, Marini AC, Pagliarin KC, Ceron MI. Eficácia da terapia para desvios fonológicos com diferentes modelos terapêuticos. Pró-Fono. 2008; 20 (3): 153-8. 28. Mezzomo, CL. Aquisição da coda no português brasileiro: uma análise via teoria de Princípios e Parâmetros. 2004. 231f. Tese (Doutorado em Letras) - Pontifícia Universidade Católica do Rio Grande do Sul, Porto Alegre.
http://dx.doi.org/10.1590/S1516-18462011005000128

RECEBIDO EM: 18/01/2011

ACEITO EM: 02/06/2011

Endereço para correspondência:

Silvana Gonçalves Lopes

Rua Justino Couto,260 Ap.216

Santa Maria - RS

CEP: 97070-500

E-mail: silvana-fono@ @otmail.com 